\title{
Paratesticular Adenomatoid Tumor
}

National Cancer Institute

\section{Source}

National Cancer Institute. Paratesticular Adenomatoid Tumor. NCI Thesaurus. Code C162476.

An adenomatoid tumor arising from the paratesticular structures. It is the most common tumor of the paratesticular region. The tail of the epididymis is the most common site of involvement. 